\title{
HIF-1 $\alpha$ as a Regulator of BMP2-Induced Chondrogenic Differentiation, Osteogenic Differentiation, and Endochondral Ossification in Stem Cells
}

\author{
Nian Zhou Ning Hua Jun-Yi Liao ${ }^{a}$ Liang-Bo Lin ${ }^{a}$ Chen Zhao ${ }^{a}$ Wei-Ke Sib

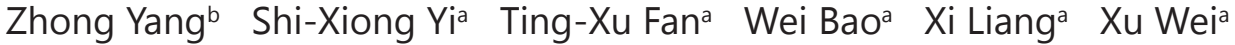 \\ Hong Chen ${ }^{\mathrm{a}}$ Cheng Chen ${ }^{\mathrm{a}}$ Qiang Chen ${ }^{\mathrm{a}} \quad$ Xin Lin $^{\mathrm{a}}$ Wei Huang ${ }^{\mathrm{a}}$
}

aDepartment of Orthopedic Surgery, The First Affiliated Hospital of Chongqing Medical University, Chongqing, bDepartment of Clinical Hematology, Third Military Medical University, Chongqing, China

\section{Key Words}

Hypoxia inducible factor- $1 \alpha$ - Bone morphogenetic protein 2 - Stem cell - Chondrogenic differentiation • Osteogenic differentiation • Cartilage tissue engineering

\begin{abstract}
Background/Aims: Joint cartilage defects are difficult to treat due to the limited self-repair capacities of cartilage. Cartilage tissue engineering based on stem cells and gene enhancement is a potential alternative for cartilage repair. Bone morphogenetic protein 2 (BMP2) has been shown to induce chondrogenic differentiation in mesenchymal stem cells (MSCs); however, maintaining the phenotypes of MSCs during cartilage repair since differentiation occurs along the endochondral ossification pathway. In this study, hypoxia inducible factor, or (HIF)- $1 \alpha$, was determined to be a regulator of BMP2-induced chondrogenic differentiation, osteogenic differentiation, and endochondral bone formation. Methods: BMP2 was used to induce chondrogenic and osteogenic differentiation in stem cells and fetal limb development. After HIF- $1 \alpha$ was added to the inducing system, any changes in the differentiation markers were assessed. Results: HIF-1 $\alpha$ was found to potentiate BMP2-induced Sox9 and the expression of chondrogenesis by downstream markers, and inhibit Runx2 and the expression of osteogenesis by downstream markers in vitro. In subcutaneous stem cell implantation studies, HIF- $1 \alpha$ was shown to potentiate BMP2-induced cartilage formation and inhibit endochondral ossification during ectopic bone/cartilage formation. In the fetal limb culture, HIF-1 $\alpha$ and BMP2 synergistically promoted the expansion of the proliferating chondrocyte zone and inhibited chondrocyte hypertrophy and endochondral ossification. Conclusion: The results of this study indicated that, when combined with BMP2, HIF-1 $\alpha$ induced MSC differentiation could become a new method of maintaining cartilage phenotypes during cartilage tissue engineering.
\end{abstract}

Copyright @ 2015 S. Karger AG, Basel

Wei Huang

KARGER 125
Department of Orthopaedic Surgery, The First Affiliated Hospital of Chongqing Medical University, No.1 Yixueyuan Road, Yuzhong District, Chongqing 400016, (China) Tel./Fax+(86)023-89011212. E-Mail huangwei68@263.net 


\section{Cellular Physiology Cell Physiol Biochem 2015;36:44-60 \begin{tabular}{l|l} 
and Biochemistry Published onIIne: AprII 27, 2015 & $\begin{array}{l}\text { C 2015 S. Karger AG, Basel } \\
\text { www.karger.com/cpb }\end{array}$ \\
\hline
\end{tabular} \\ Zhou et al.: HIF-1 $\alpha$ Regulates BMP2-Induced Osteochondrogenic Differentiation}

\section{Introduction}

Joint cartilage defects resulting from degenerative disorders or traumatic injuries are difficult to treat due to the cartilage's limited capacity for self repair [1]. Numerous surgical methods have been applied in an effort to repair cartilage, reduce joint pain, and improve joint function, primarily marrow stimulating techniques and transplantation techniques [2]. However, marrow stimulating techniques, such as abrasion arthroplasty, pridie drilling, and microfracture, have failed to generate satisfactory clinical results [2, 3]. In addition, the application of transplantation techniques, such as osteochondral autologous transplantation and autologous chondrocyte implantation, are limited by insufficient amounts of healthy non-weight-bearing joint cartilage, donor site morbidity, loss of chondrocytic phenotypes during expansion, and immunological reactions [2,3]. As a result, the use of stem cells and gene enhancement to engineer cartilage has become a viable alternative to other cartilage repair methods $[1,2,4]$.

Isolated from bone marrow [5], trabecular bone chips [6], adipose tissue [7], periosteum [8], perichondrium [9] and other tissues [10], mesenchymal stem cells (MSCs) have been proven to be capable of expanding through multiple passages without losing their ability to undergo chondrogenic, osteogenic, and adipogenic differentiation [11-14]. Because of this, MSCs are considered ideal seed cells for cartilage tissue engineering. However, the successful generation of stable hyaline cartilage tissue using MSCs requires the efficient delivery of the factors stimulating chondrogenesis $[1,15]$. Many studies have reported that certain growth factors, such as transforming growth factor (TGF)- $\beta s[16,17]$, bone morphogenetic proteins (BMPs) [18, 19], fibroblast growth factors (FGFs) [20], and insulin-like growth factor (IGF)-1 $[21,22]$, are capable of directing MSCs to chondrocyte phenotypes. However, these growth factors have not been extensively used due to their limited abilities to synthesize specific cartilage matrix components. Hence, the optimization of growth factors and the regulation of their contributions to chondrogenesis is crucial.

Bone morphogenetic protein 2 (BMP2), which belongs to the TGF- $\beta$ super-family, plays an essential role in the regulation of chondrocyte proliferation and maturation during endochondral bone development in vivo [23]. This protein has also been proven to induce chondrogenic differentiation in various types of stem cells, such as human mesenchymal stem cells (hMSCs) [24], adipose-derived stem cells (ADSCs) [22], and mouse embryonic fibroblasts (MEFs) [25], in vitro. BMP2 has also been proven to be more capable of inducing MSC chondrogenic differentiation than other growth factors, such as TGF- $\beta$ s and IGF-1 [26]. However, BMP2 also induces MSC osteogenic differentiation [24] and stimulates endochond ral ossification [23]. Thus, potentiating BMP2-induced MSC chondrogenic differentiation while inhibiting BMP2-induced MSC osteogenic differentiation and endochondral ossification could be vital to maintaining hyaline-like cartilage phenotypes during cartilage tissue engineering. Sox9 is known to be a critical factor during chondrogenic differentiation [25], but Runx2 is a critical factor during osteogenic differentiation and endochondral ossification [27] that stimulates hypertrophic chondrocyte maturation [28]. Both of these factors can be regulated by BMP2 during the osteochondrogenic differentiation of stem cells in vivo and vitro [25, 27]. Therefore, potentiating Sox 9 expression and inhibiting Runx2 expression via regulator optimization could promote BMP2-induced MSC chondrogenic differentiation, inhibit endochondral ossification, and maintain cartilage phenotypes.

Hypoxia inducible factor, or (HIF)- $1 \alpha$, which is a master regulator of hypoxia, plays an important role during the osteochondrogenic differentiation of stem cells $[29,30]$. HIF- $1 \alpha$ has been proven to bind to Sox9 promoters, activate Sox9 expression, and enhance Sox9mediated transcriptional activity during chondrogenesis [30-32]. HIF-1 $\alpha$ has also been shown to inhibit MSC osteogenesis by directly downregulating Runx2 via TWIST [33]. Some studies have concluded that the stabilization of HIF- $1 \alpha$ in normoxic conditions could be a new method of stabilizing cartilage phenotypes [34]. Thus, HIF-1 $\alpha$ could adequately regulate BMP2-induced MSCs chondrogenic differentiation, osteogenic differentiation, 
and endochondral ossification, cartilage phenotype maintenance during cartilage tissue engineering.

In this study, the use of HIF-1 $\alpha$ to potentiate BMP2-induced MSC chondrogenic differentiation, inhibit osteogenic differentiation and endochondral ossification, and maintain cartilage phenotypes was investigated. HIF-1 $\alpha$ was determined to be capable of potentiating BMP2-induced Sox9 and the expression of chondrogenesis in downstream markers, while inhibiting Runx 2 and the expression of osteogenesis in downstream markers in vitro. In the subcutaneous stem cell implantation studies, HIF-1 $\alpha$ was proven to potentiate BMP2-induced cartilage formation and inhibit endochondral ossification during ectopic bone/cartilage formation. In the fetal limb culture, HIF- $1 \alpha$ and BMP2 were determined to synergistically promote the expansion of the proliferating chondrocyte zone and inhibit chondrocyte hypertrophy and ossification. The results of this study indicated that BMP2, when combined with HIF- $1 \alpha$, induced MSC differentiation and could become a new method of maintaining chondrocyte phenotypes during cartilage tissue engineering.

\section{Materials and Methods}

HEK-293 cells and the C3H10T1/2 cell line culture

The HEK-293 cells and mesenchymal stem cell line (C3H10T1/2) used in this study were purchased from the American Type Culture Collection (ATCC; USA). They were maintained in Dulbecco modified Eagle medium (DMEM) (Hyclone, USA) supplemented with 10\% fetal bovine serum (Hyclone, USA), 100 $\mathrm{U}$ penicillin, and $100 \mathrm{mg}$ streptomycin (Beyotime, China). They were incubated at $37^{\circ} \mathrm{C}$ in a humidified atmosphere containing $5 \% \mathrm{CO}_{2}$ and $95 \%$ air. The cells were passaged with trypsin (Hyclone, USA) when they were approximately $85 \%$ confluent.

Recombinant Adenoviruses Expressing GFP, BMP2, and Sox9

Recombinant adenoviruses were generated using AdEasy technology [35]. The human BMP2 and human HIF- $1 \alpha$ coding regions were polymerase-chain-reaction (PCR)-amplified, cloned into an adenoviral shuttle vector, and subsequently used to generate recombinant adenoviruses in the HEK-293 cells. The primers used to amplify the coding regions included HIF-1 $\alpha$ F: 5'-AGGGGATCCACCATGGAGGGCGCCGGCG GCGCGAACGAC-3',R:5'-TGCTCTAGATTAGTTAACTTGATCCAAAGCTCTGAG-3';BMP2F:5' -CCCAAGCTTACCA CCATGGTGGCCGGGACCCGCTGTCTTC-3',R:5'-CGCGGATCCCTAGCGACACCCACAACCCTCCAC-3'.BamH I and Xba I enzymes were used to clone the HIF-1 $\alpha$ coding regions into the shuttle vector. BamH I and Hind3 enzymes were used to clone the BMP2 coding regions into the shuttle vector. The resulting adenoviruses were denoted AdBMP2, AdHIF-1 $\alpha$, and AdGFP. AdBMP2 also expressed green fluorescent protein (GFP), whereas AdHIF-1 $\alpha$ expressed red fluorescent protein (RFP) markers, which were used to monitor the infection efficiency via fluorescence microscopy (Nikon TE200-U, Japan). AdGFP, which only expressed GFP, was used as the control.

Micromass chondrogenesis cultures

Micromass cultures created with C3H10T1/2 cells were used to effectively study in vitro chondrogenesis since these cells do not spontaneously differentiate under normal culture conditions [36], necessitating the addition of exogenous factors, such as BMP2 and HIF-1 $\alpha$, into the culture medium [37]. This made it easier to study the effects of these factors on the C3H10T1/2 cell differentiation potential. Twenty-four hours after AdBMP2, AdHIF-1 $\alpha$, AdBMP2+AdHIF-1 $\alpha$, and AdGFP were injected, the micromass cultures were prepared as previously described [36, 37]. The cultures were grown at a density of $1.5 \times 10^{7}$ cells $\cdot \mathrm{mL}-1$ in DMEM supplemented with $10 \%$ FBS; then, $40-\mu \mathrm{L}$ cell suspension droplets were inoculated into the centers of 12 -well plates (Corning, USA). Then, after the cells were allowed to combine for 1.5 hours at $37^{\circ} \mathrm{C}$ under $5 \% \mathrm{CO}_{2}$, the plates were flooded with the culture medium, which was changed every other day. The day of inoculation was considered to be culture day zero. The micromass cultures were maintained for up to nine days. 


\section{Cellular Physiology Cell Physiol Biochem 2015;36:44-60 \begin{tabular}{l|l} 
and Biochemistry Published onIIne: April 27, 2015 & $\begin{array}{l}\text { C) 2015 S. Karger AG, Basel } \\
\text { www.karger.com/cpb }\end{array}$ \\
\hline
\end{tabular}

\section{Alcian blue staining}

The sulfated glycosaminoglycans (GAGs) produced by the micromass cultures were investigated using Alcian blue staining after seven and nine days. The micromass cultures were rinsed with phosphatebuffered saline (PBS) and fixed in 4\% paraformaldehyde for 15 minutes. They were subsequently stained with Alcian blue solution (Sigma-Aldrich, Germany) at room temperature as previously described [37] and then photographed.

Alkaline phosphatase (ALP) activity assays

C3H10T1/2 cells were seeded in 24-well plates and infected with AdBMP2, AdHIF-1 $\alpha$, AdBMP2+AdHIF$1 \alpha$, and AdGFP. Seven and nine days after the infection, the samples were fixed with a fixative solution containing citrate and acetone, for 30 seconds at room temperature. Next, the cell samples were incubated with Alkaline Dye Mixture (Sigma-Aldrich, Germany) at room temperature for 10-60 minutes, and the resulting staining were monitored under a microscope (Nikon TE200-U) every 5 minutes. Photographs were collected. Each of the chemiluminescence assay conditions were replicated three times. The tests were replicated in at least three independent experiments.

\section{Calcium deposition}

C3H10T1/2 cells were seeded in 24-well plates and infected with AdBMP2, AdHIF-1 $\alpha$, AdBMP2+AdHIF$1 \alpha$, and AdGFP. The infected cells were cultured in a mineralization medium containing ascorbic acid (50 $\mu \mathrm{g} / \mathrm{mL})$ and $\beta$-glycerophosphate $(10 \mathrm{mM})$. Seven and nine days after infection, the mineralized matrix was stained for calcium precipitation using Alizarin red S staining as previously described [36, 38]. The cells were fixed with $0.05 \%(\mathrm{v} / \mathrm{v})$ glutaraldehyde at room temperature for 10 minutes. After being washed with distilled water, the fixed cells were incubated with $0.4 \%$ Alizarin red S (Sigma-Aldrich, Germany) for 5 minutes then extensively washed with distilled water. The calcium mineral deposit stainings were photographed under a microscope (Nikon TE200-U).

\section{Cell for RNA isolation and protein isolation}

C3H10T1/2 cells were seeded at a density of $1 \times 10^{5}$ cells/well in six-well plates (Corning) containing DMEM supplemented with 10\% FBS, and then infected with AdBMP2, AdHIF-1 $\alpha$, AdBMP2+AdHIF-1 $\alpha$, and AdGFP. The culture medium was changed on every second day. They were incubated at $37^{\circ} \mathrm{C}$ in a humidified atmosphere containing 5\% CO2 and 95\% air.

\section{RNA isolation and semiquantitative reverse transcription-PCR}

Total RNA was extracted with Trizol reagent (Invitrogen, USA) at different times. An iScript cDNA synthesis kit (Bio-Rad, USA) was used to generate cDNA templates from the total RNA through reverse transcription (RT). The first-strand cDNA products were further diluted and used as PCR templates. The PCR primers (Table 1) were designed using Primer 3.0 (ABI Coperation, USA) to amplify the genes of interest (approximately 150-180 bp). Semiquantitative RT-PCR was conducted as described previously [39]. The cDNA was amplified in a $25-\mu \mathrm{L}$ PCR mix. The following touchdown cycling program was used: $94^{\circ} \mathrm{C}$ for $2 \mathrm{~min}$ for 1 cycle; $92^{\circ} \mathrm{C}$ for $20 \mathrm{~s}, 68^{\circ} \mathrm{C}$ for $30 \mathrm{~s}$, and $72^{\circ} \mathrm{C}$ for 12 cycles decreasing $1^{\circ} \mathrm{C}$ per cycle; and then $92^{\circ} \mathrm{C}$ for $20 \mathrm{~s}, 57^{\circ} \mathrm{C}$ for $30 \mathrm{~s}$, and $72^{\circ} \mathrm{C}$ for $20 \mathrm{~s}$ for $20-25$ cycles, depending on the abundance of a given gene. The PCR products were resolved on $2 \%$ agarose gel. All of the samples were normalized with the GAPDH expression level.

Table. 1. Oligonucleotide primers utilized for RT-PCR amplification

\begin{tabular}{cllr}
\hline Target & Forward primer sequence & Reverse primer sequence & Base pairs \\
\hline GAPDH & 5'-CTACACTGAGGACCAGGTTGTCT-3' & 5'-TTGTCATACCAGGAAATGAGCTT-3' & 123bp \\
HIF-1 $\alpha$ & 5'-TGCATCTCCATCTCCTACCC-3' & 5'-CGTTAGGGCTTCTTGGATGA-3' & 152bp \\
BMP2 & 5'-GCGTCAAGCCAAACACAA-3' & 5'-CATGATAGCCCGGAGGTG-3' & $122 \mathrm{bp}$ \\
Col2A1 & 5'-CAACACAATCCATTGCGAAC-3' & 5'-TCTGCCCAGTTCAGGTCTCT-3' & $159 \mathrm{bp}$ \\
Aggrecan & 5'-TGGCTTCTGGAGACAGGACT-3' & 5'-TTCTGCTGTCTGGGTCTCCT-3' & $188 \mathrm{bp}$ \\
Col1A1 & 5'-GAGCGGAGAGTACTGGATCG-3' & 5'-GCTTCTTTTCCTTGGGGTTC-3' & $158 \mathrm{bp}$ \\
ALP & 5'-GCTCTCCGAGATGGTGGA-3' & 5'-AGCCTGCTTGGCCTTACC-3' & $121 \mathrm{bp}$ \\
\hline
\end{tabular}




\section{Cellular Physiology Cell Physiol Biochem 2015;36:44-60 \begin{tabular}{l|l} 
and Biochemistry Published onIIne: April 27, 2015 & $\begin{array}{l}\text { C 2015 S. Karger AG, Basel } \\
\text { www.karger.com/cpb }\end{array}$ \\
\hline
\end{tabular} \\ Zhou et al.: HIF-1 $\alpha$ Regulates BMP2-Induced Osteochondrogenic Differentiation}

Real-time PCR

Real-time PCR was conducted as described previously [40]. The cDNA was amplified in a 10- $\mu \mathrm{L}$ PCR mix containing $5 \mu \mathrm{L}$ of SYBR Green Super Mixture (Bio-Rad). A real-time PCR was conducted with a CFX-Connect Real-Time PCR system (Bio-Rad) for 3 minutes at $95^{\circ} \mathrm{C}$, followed by 40 cycles at $95^{\circ} \mathrm{C}$ for 10 seconds and $58^{\circ} \mathrm{C}$ for 5 seconds. The efficiency and specificity values of each primer set were confirmed by comparing the standard curves of the threshold cycle $\left(\mathrm{C}_{\mathrm{t}}\right)$ values to the RNA serial dilutions and melting profile evaluations. The $C_{t}$ values were normalized using GAPDH in order to manage any cDNA quantification differences. The results were reported as relative expression levels.

\section{Western blotting analysis}

Cells were collected using a Lysis Buffer (Beyotime, China). The cleared total cell lysate was denatured via boiling and resolved via $10 \%$ sodium dodecyl sulfate polyacrylamide gel electrophoresis. After electrophoretic separation, the proteins were transferred to a polyvinylidene fluoride membrane (Bio-Rad). The membrane was blocked with $5 \%$ skim milk for 1 hour at room temperature, and probed overnight with anti-Sox9, anti-Runx2, anti-COL2A1, anti-OPN, anti-OCN, and anti- $\beta$-actin (Santa Cruz Biotechnology, USA; $1: 500$ ) at $4^{\circ} \mathrm{C}$. After five washes, the blots were incubated with a goat anti-rabbit or rabbit anti-mouse peroxidase-conjugated secondary antibody (Abcam, USA; 1:1000) for 2 houea at room temperature. The blots were displayed with Immobilon Western Chemiluminescent HRP Substrate (Millpore, USA). The results of the relative protein expression levels were compared to that of $\beta$-actin using Quantity One software (BioRad, Quantity One 4.6.2).

\section{Subcutaneous stem cell implantation}

C3H10T1/2 cells were infected with AdBMP2, AdHIF-1 $\alpha$, AdBMP2+AdHIF-1 $\alpha$, and AdGFP. Twentyfour hours after infection, the cells were harvested and resuspended in PBS for subcutaneous injection (5 $\times$ $10^{6}$ /injection) into the flanks of athymic nude (nu/nu) mice (groups of four 4- to 6-week-old males, Beijing HFK Bioscience Corporation, China). All of the experiments involving animals were performed according to institutional animal guidelines (Ethics Committee of Chongqing Medical University). Five weeks after implantation, the animals were euthanized, and the bone masses of the implantation sites were retrieved for histological evaluation and other staining procedures.

Hematoxylin and eosin, Alcian blue, safranin O-fast green, and Masson trichrome staining

The retrieved tissues were fixed in $4 \%$ paraformaldehyde, decalcified, and embedded in paraffin. Serial sections of the embedded specimens were stained with hematoxylin and eosin, Alcian blue, safranin O-fast green, and Masson trichrome staining according to the previously described protocols [38].

\section{Mouse Fetal Limb Explant Cultures}

The forelimbs of mouse embryos (E18.5) were dissected under sterile conditions and incubated in DMEM (Hyclone, China), which contained 0.5\% FBS (Gibco, Australia), $50 \mathrm{mg} / \mathrm{ml}$ ascorbic acid, $1 \mathrm{mM}$ $\beta$-glycerophosphate, $100 \mathrm{U} / \mathrm{ml}$ penicillin, and $100 \mathrm{mg} / \mathrm{ml}$ streptomycin, at $37^{\circ} \mathrm{C}$ in humidified air with $5 \% \mathrm{CO}^{2}$ for as many as fourteen days [38]. The limbs were directly infected with AdBMP2, AdHIF-1 $\alpha$, AdBMP2+AdHIF-1 $\alpha$, and AdGFP 12 hours after dissection. Approximately 50\% of the culture medium was replaced every two days. On day twelve, $100 \mathrm{mM}$ calcein (Sigma) was added to the medium in order to observe any new bone formation. The cultured forelimbs were observed under a microscope at different times in order to confirm the tissue cell survival and fluorescent marker expression. Then, the forelimb developments were analyzed.

\section{Statistical analysis}

Each of the quantitative assay conditions were replicated three times, and all of the results were validated with a minimum of three independent experiments. The data was expressed in terms of mean \pm standard deviation (SD). Any statistically significant differences among the samples were assessed using a one-way variance analysis (SPSS coperation, SPSS 17.0), in which a $p$-value less than $0.05(p<0.05)$ was considered statistically significant.

\section{KARGER}




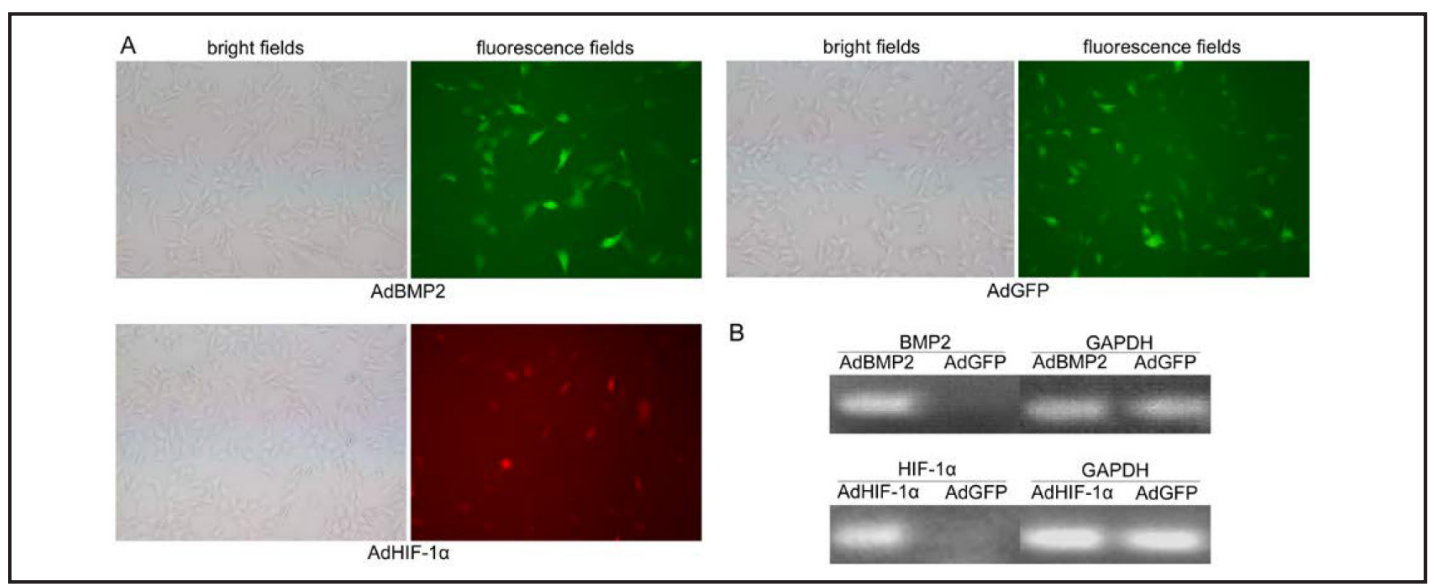

Fig. 1. The successful infection of the C3H10T1/2 cells with AdBMP2, AdHIF-1 $\alpha$, and AdGFP, and the effective exogenous expression of BMP2 and HIF-1 $\alpha$ during nomoxia. A: C3H10T1/2 cells were infected with AdBMP2, AdHIF-1 $\alpha$, and AdGFP in plate cultures. The expression of the monomeric GFP and RFP marker genes was detected 24 hours after infection under both bright and fluorescent fields (100X). B: The total RNA was isolated 30 hours after infection and used to generate cDNA templates; then, they were subjected to semi-quantitative RT-PCR reactions. The exogenous expression of HIF- $1 \alpha$ was assessed with semi quantitative RT-PCR using primer pairs specific to human HIF- $1 \alpha$. The PCR products were resolved on $2 \%$ agarose gel and visualized under an ultraviolet lamp. The GAPDH and BMP2 levels were detected using the same method.

\section{Results}

The C3H10T1/2 cells infected with AdBMP2, AdHIF-1 $\alpha$, or AdGFP exogenously expressed BMP2 and HIF-1 $\alpha$

In order to determine the effects of HIF-1 $\alpha$ on BMP2-induced chondrogenic and osteogenic differentiation, recombinant adenoviruses that expressed mouse BMP2 and human HIF-1 $\alpha$ during normoxia were generated. The AdHIF-1 $\alpha$, AdBMP2, and AdGFP adenoviruses effectively infected the C3H10T1/2 cells, as was indicated by the visualization of green and red fluorescence. Seventy percent of the cells were positive for GFP and $50 \%$ of the cells were positive for RFP 24 hours after infection (Fig. 1A). The semiquantitative RT-PCR analysis revealed HIF- $1 \alpha$ and BMP2 expression in the C3H10T1/2 cells infected with AdHIF-1 $\alpha$ and AdBMP2, respectively, (Fig. 1B) but not in those infected with AdGFP.

The data indicated that the AdBMP2- and AdHIF-1 $\alpha$-infected cells effectively expressed BMP2 and HIF- $1 \alpha$, respectively, during normoxia. Thus, these cells were suitable for further experimental use.

HIF-1 $\alpha$ potentiated BMP2-induced chondrogenic differentiation in the micromass cultures in vitro

The effects of HIF-1 $\alpha$ on BMP2-induced chondrogenic differentiation in the C3H10T1/2 cells were investigated using the micromass cultures. The C3H10T1/2 cells were infected with AdBMP2, AdHIF-1 $\alpha$, AdBMP2+AdHIF- $1 \alpha$, and AdGFP and developed in micromass cultures. The resulting micromasses, which were established 24 hours later, were examined for green and red fluorescence in order to monitor the infection efficiencies of the adenoviruses (Fig. 2A). Using the western blotting method, chondrogenic differentiation was evaluated by determining whether Sox 9 protein, a critical factor for chondrogenesis, was expressed. Compared to the BMP2 group, the HIF- $1 \alpha$ component of the BMP2+HIF- $1 \alpha$ group significantly enhanced BMP2-induced Sox9 protein expression on days one and three $(P<0.05)$ (Figs. 2B and 2C).

The expression of the Sox9 downstream response genes, type II collagen (COL2A1) and aggrecan, was also evaluated at the mRNA level using real-time PCR after five, seven, and nine

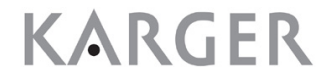


A
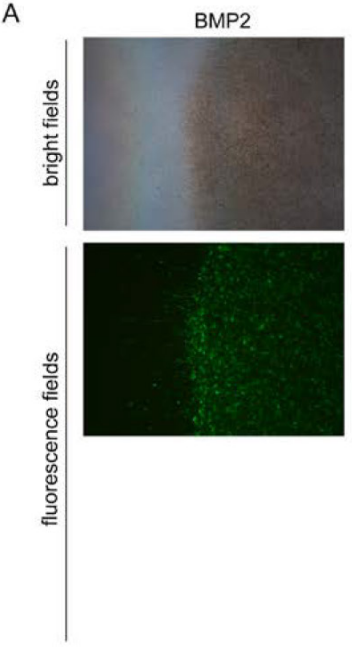

B

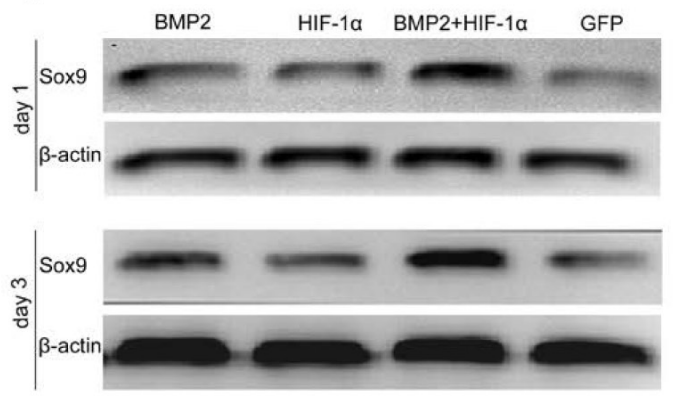

HIF-1 $\alpha$
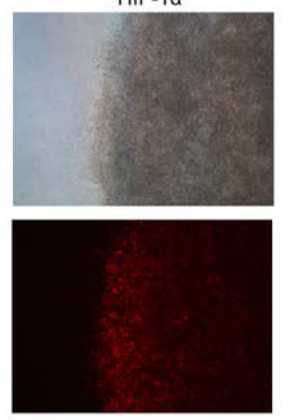$$
\text { . }
$$

$$
\text { C }
$$

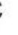
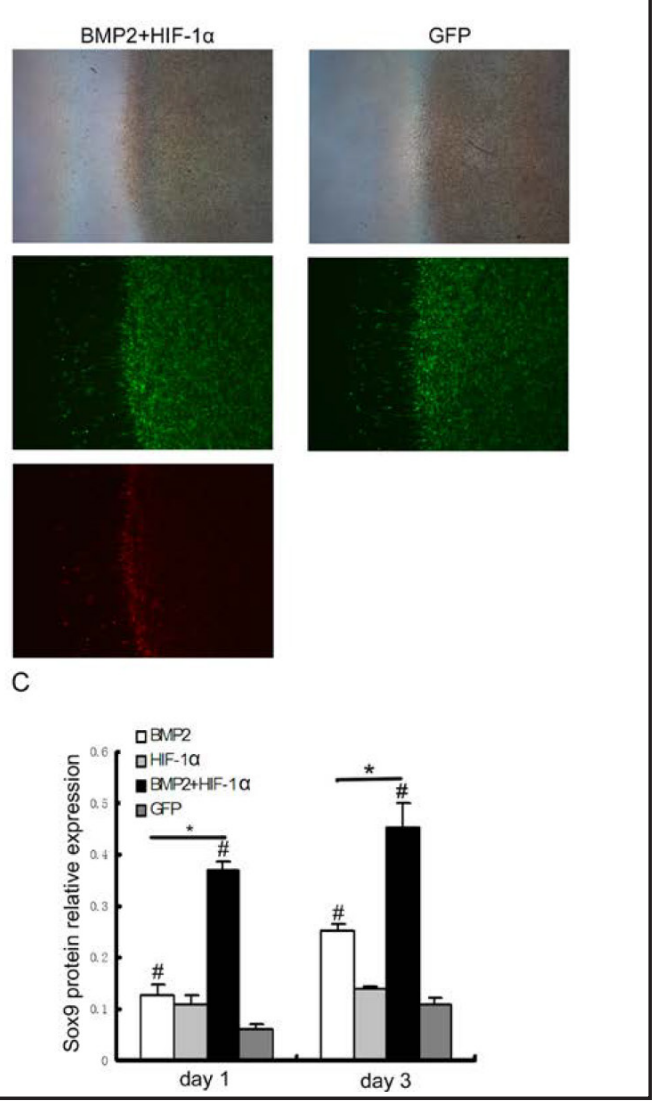

Fig. 2. The micromass cultures and expression of critical factor Sox 9 during chondrogenic differentiation. The C3H10T1/2 cells were cultured in micromasses after being infected with AdBMP2, AdHIF-1 $\alpha$, AdBMP2+AdHIF-1 $\alpha$, and AdGFP. A: The micromass cultures were conducted as previously described. The expression of the monomeric GFP and RFP marker genes was detected 24 hours after inoculation under both bright and fluorescent fields (40X). B and C: The Sox 9 protein levels were measured after 1 and 3 days using the Western blot method; HIF-1 $\alpha$ potentiated BMP2-induced Sox 9 protein expression at both time. All of the relative protein expression level results were compared to those of $\beta$-actin using Quantity one. The data was denoted in terms of mean \pm SD. \#: $P<0.05$ vs. GFP; *: $P<0.05$, BMP2 vs. BMP2+HIF- $1 \alpha$.

days. HIF-1 $\alpha$ significantly increased the expression of both of these chondrogenic markers $(P<0.05)$ (Figs. 3A and 3B). In addition, an examination of the COL2A1 protein expression yielded the same results as the mRNA expression examination $(P<0.05)$ (Figs. 3C and 3D). In order to investigate the production of cartilaginous matrix components, the cultures were stained with Alcian blue. The results indicated that HIF-1 $\alpha$ enhanced the BMP2-induced secretion of sulfated GAGs in the cartilaginous matrix after seven and nine days (Fig. 3E).

These results suggested that HIF-1 $\alpha$ could potentiate BMP2-induced chondrogenic differentiation in vitro.

HIF-1 $\alpha$ inhibited BMP2-induced osteogenic differentiation in the plate culture in vitro

In addition to its role in chondrogenesis, BMP2 is involved in osteogenesis since it activates Runx2. Thus, the effects of HIF-1 $\alpha$ on BMP2-induced osteogenic differentiation were investigated. Western blot assays conducted one and three days after culturing indicated that HIF- $1 \alpha$ obviously inhibited the BMP2-induced expression of Runx2 during osteogenesis $(P<0.05)$ (Figs. 4A and 4B).

ALP and type I collagen (COL1A1) are the downstream response genes of Runx2. Therefore, the expression of ALP and COL1A1 mRNA was evaluated using real-time PCR on days seven and nine. HIF-1 $\alpha$ inhibited BMP2-induced ALP and COL1A1 mRNA expression $(P$

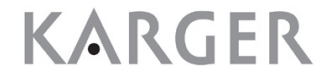




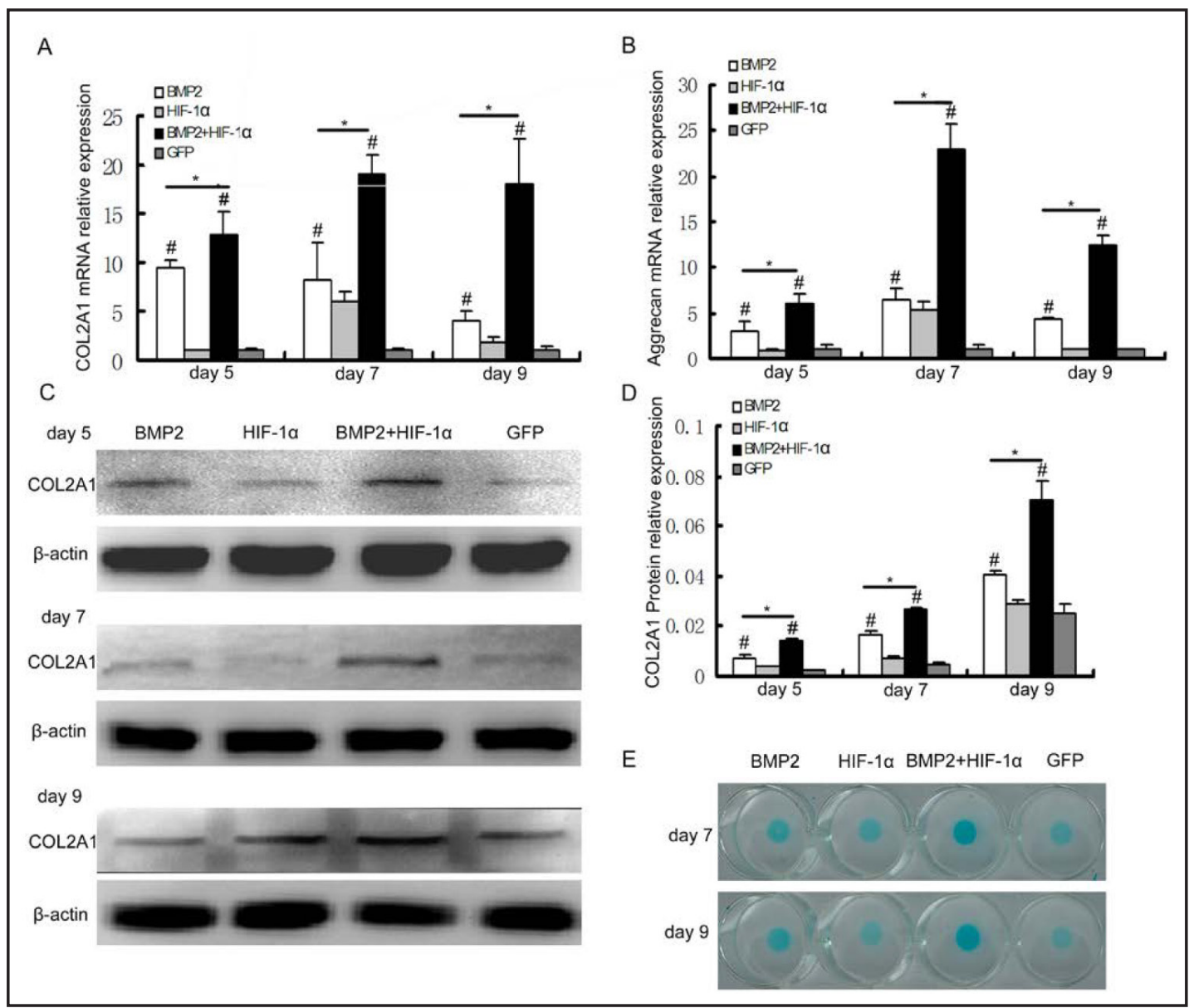

Fig. 3. HIF-1 $\alpha$ potentiated the BMP2-induced expression of chondrogenic differentiation markers. A and B: The expression of the HIF-1 $\alpha$-enhanced, BMP2-induced Sox 9 downstream response genes, including COL2A1 and aggrecan, at the mRNA level obtained by real-time PCR after 5, 7, and 9 days. C and D: HIF-1 $\alpha$ also enhanced BMP2-induced COL2A1 protein expression as determined by the Western blot metnod. E: Sulfated glycosaminoglycan (GAGs) production. The production of GAGs was investigated in micromass cultures using Alcian blue staining after 7 and 9 days. HIF- $1 \alpha$ obviously enhanced the BMP2-induced secretion of sulfated GAGs after 7 and 9 days. All of the relative protein expression level results were compared to those of $\beta$-actin using Quantity one. The data is denoted in terms of mean \pm SD. \#: $P<0.05$ vs. GFP; * $P<0.05$, BMP2 vs. BMP2+HIF-1 $\alpha$.

$<0.05$ ) (Figs. 4C and 4D). In order to further explore the inhibitory effects of HIF-1 $\alpha$ on BMP2induced osteogenic differentiation, ALP activity assays were conducted at varying times. The results of the staining and relative activity assays indicated that HIF- $1 \alpha$ also significantly inhibited BMP2-induced ALP activity on days seven and nine ( $P<0.05)$ (Figs. 4E and 4F).

The expression of the late osteogenic markers, osteocalcin (OCN) and osteopontin (OPN), were also examined using western blot assays. The OCN and OPN protein expression was reduced by HIF- $1 \alpha$; moreover, the relative expression of OCN and OPN was significantly lower in the AdBMP2+AdHIF-1 $\alpha$ group than in the AdBMP2 group on days seven and nine $(P$ $<0.05$ ) (Figs. 5A and 5B). In order to conduct the matrix mineralization assays, C3H10T1/2 cells were infected with the indicated adenoviruses and cultured in a mineralization medium. Alizarin red S staining was completed seven and nine days after infection. The staining indicated that HIF-1 $\alpha$ inhibited BMP2-induced late-stage osteogenic differentiation (Fig. 5D).

These results demonstrated that HIF- $1 \alpha$ could significantly inhibit BMP2-induced earlyand late-stage osteogenic differentiation in vitro.

\section{KARGER}




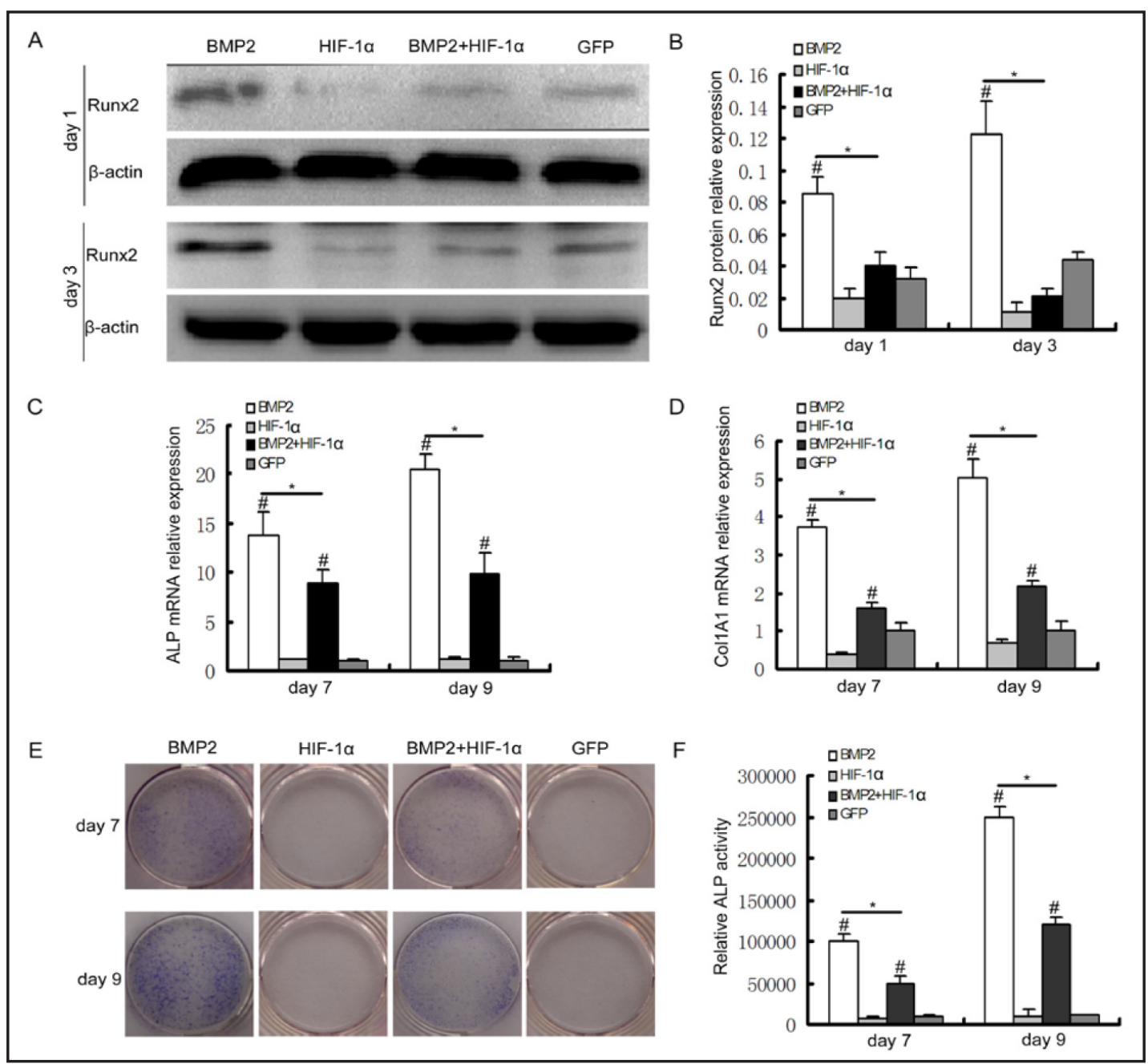

Fig. 4. Inhibition of BMP2-induced early stage osteogenic markers by HIF-1 $\alpha$. A and B: HIF-1 $\alpha$-inhibited Runx2 protein expression during BMP2-induced osteogenic differentiation on days 1 and 3. C and D: ALP and COL1A1 expression were inhibited at the mRNA level as determined by real-time PCR. E and F: ALP staining and relative activity assays were also conducted at varying times. The staining results shown were obtained on days 7 and 9 days. All of the relative protein expression level results were compared to those of $\beta$-actin using Quantity one. The data was denoted in terms of mean \pm SD. \#: $P<0.05$ vs. GFP; * $P<0.05$, BMP2 vs. BMP2+HIF-1 $\alpha$.

HIF-1 $\alpha$ inhibited BMP2-induced osteogenic differentiation and endochondral ossification and maintained the chondrocyte phenotypes during the stem cell implantations in vivo

The above assays established that HIF-1 $\alpha$ played two different roles during BMP2induced chondrogenic differentiation and osteogenic differentiation in vitro. BMP2 was involved in the regulation of chondrocyte development and in some activities during endochondral ossification [23]. Therefore, in this study, we aimed to demonstrate the role of HIF-1 $\alpha$ during BMP2-induced osteochondrogenic differentiation in vivo. The C3H10T1/2 cells were determined to be effectively infected with AdBMP2, AdHIF-1 $\alpha$, AdBMP2+AdHIF$1 \alpha$, and AdGFP, as previously indicated. The infected cells were collected and injected subcutaneously into the athymic nude mice.

After 5 weeks, the animals were euthanized, and the bony masses were retrieved (Fig. 6A). The C3H10T1/2 cells infected with either AdHIF-1 $\alpha$ or AdGFP alone did not yield any detectable masses (data not shown). The bony mass volumes of the AdBMP2 and AdBMP2+AdHIF-1 $\alpha$ groups did not significantly differ $(P>0.05)$ (Fig. 6B). Based on a 


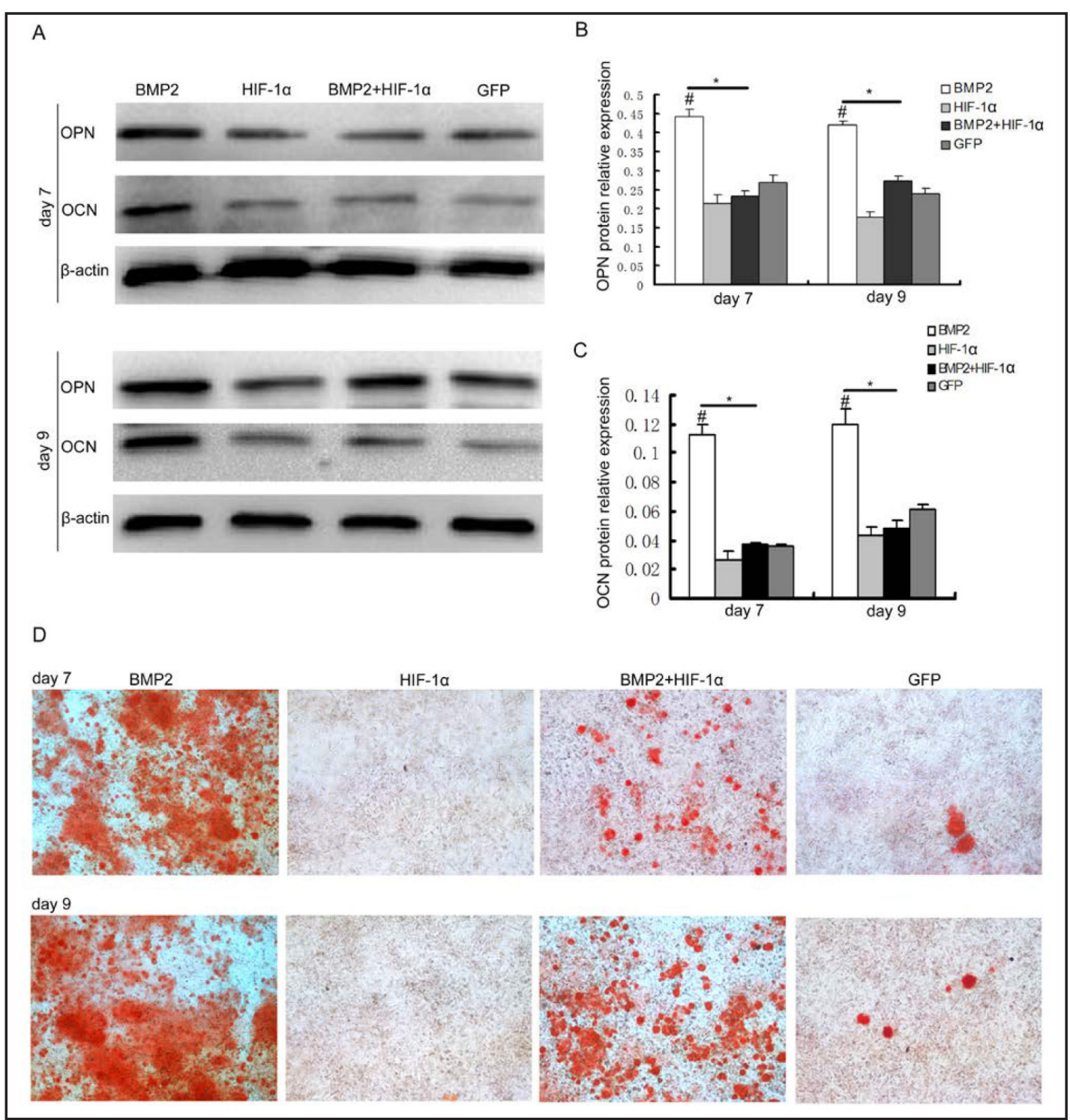

Fig. 5. Inhibition of BMP2-induced late stage osteogenic markers by HIF-1 $\alpha$. A and B: OCN and OPN expression were also inhibited by HIF-1 $\alpha$; the relative protein expression levels on days 7 and 9 are shown. C: C3H10T1/2 cells infected with adenoviruses. Alizarin Red S staining was conducted 7 and 9 days after infection, The calcium mineral deposit stainings were recorded under microscopy (100X). All of the relative protein expression level results were compared to those of $\beta$-actin using Quantity one. The data is denoted in terms of mean \pm SD. \#: $P<0.05$ vs. GFP; *: $P<0.05$, BMP2 vs. BMP2+HIF- $1 \alpha$.

histological examination conducted with hematoxylin and eosin, Alcian blue, Safranin O-fast green, and Masson trichrome staining, the cells stimulated with both BMP2 and HIF- $1 \alpha$ were formed more cartilage with minimal bone matrices and trabeculae, but the BMP2-transduced cells formed less cartilage and more mature bone matrices and thicker trabeculae, with some hypertrophic chondrocytes (Figs. 6C and 6D). The AdBMP2+AdHIF-1 $\alpha$ groups had higher trabecular area percentages than the AdBMP2 groups $(P<0.05)$ (Fig. 6E).

From the results obtained in vivo, HIF- $1 \alpha$ was found to be capable of enhancing BMP2induced chondrogenesis while inhibiting the formation of bone matrices, trabeculae, and endochondral ossification; thus, it maintained the chondrocyte phenotypes during osteochondrogenic differentiation in vivo. 


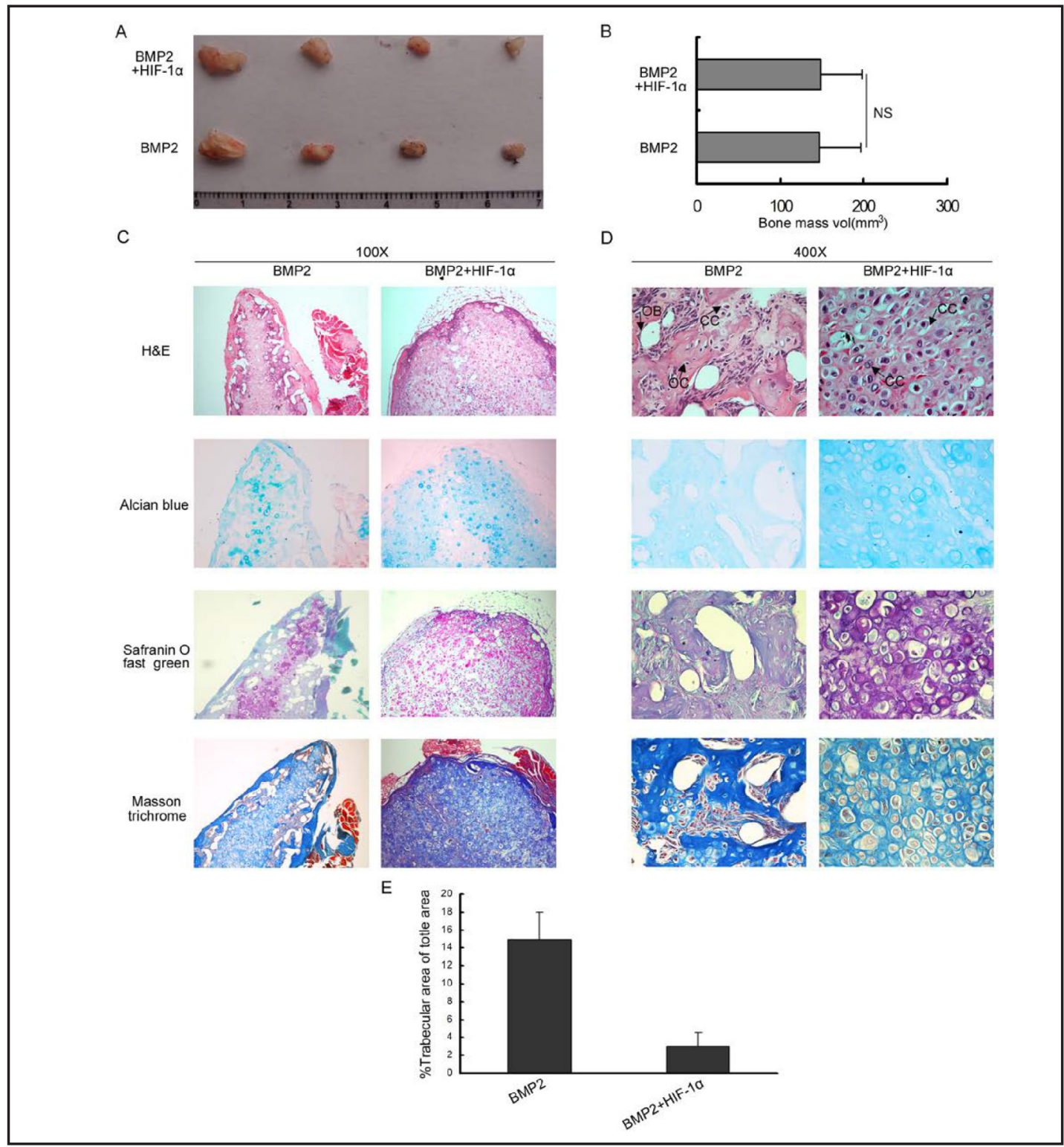

Fig. 6. HIF1 $\alpha$ potentiated BMP2-induced chondrogenesis, inhibited osteogenic differentiation and endochondral ossification, and maintained the chondrogenic phenotypes in vivo. A: Macrographic images of the ectopic bone masess. Both BMP2- and HIF-1 $\alpha$-tranduced MSCs were implanted subcutaneously. The ectopic osseous masses were retrieved after 5 weeks. B: The vcell formation volumes of the bony masses were evaluated. C and D: Histologic evaluations of the retrieved bone masses. The bone masses retrieved from the BMP2 and BMP2+HIF-1 $\alpha$-induced groups were fixed and decalcified. Hematoxylin and eosine (H\&E), Alcian blue, safranin O-fast green, and Masson's trichrome stainings were used as shown in Fig. 6C (100X) and Fig. 6D (400X). E: The trabecular area percentages of both groups were determined using Image J software. OB: Osteoblast, OC: Osteocyte, CC: Chondrocyte. NS: $P>0.05$.

HIF-1 $\alpha$ promoted the expansion of the proliferating chondrocyte zone and inhibited BMP2-induced chondrocyte hypertrophy and endochondral ossification in the fetal limb explant cultures

In order to precisely observe the effects of HIF-1 $\alpha$ on the BMP2-induced progression of chondrogenesis and endochondral ossification, fetal limb cultures were conducted. The skinned fetal limbs were isolated from the E18.5 perinatal mouse embryos and cultured in an organ culture medium in the presence of AdGFP, AdBMP2, and/or AdHIF-1 $\alpha$ for fourteen 


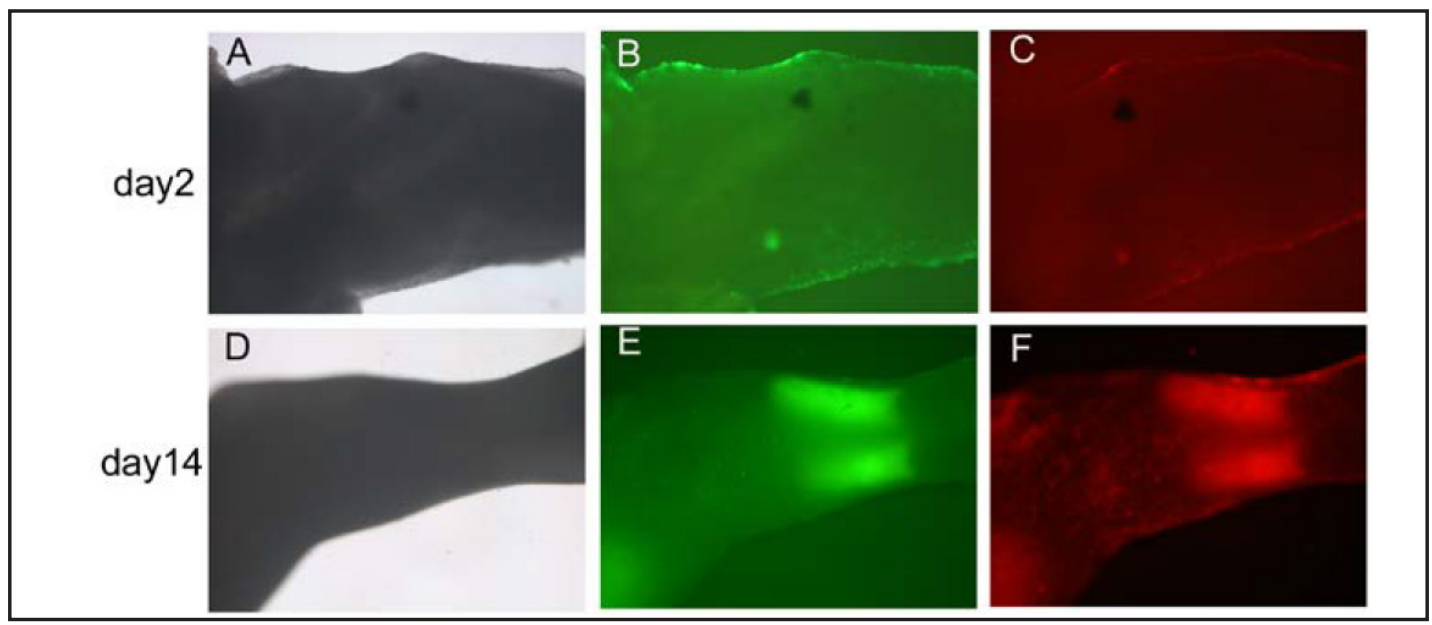

Fig. 7. Mouse E18.5 forelimbs ( $\mathrm{n}=$ four mice in each group) were cultured in an organ culture medium, and their transduction efficiencies and the ossification of new bone dyed with calcein were visualized under a bright fluorescent field (40X). A: The forelimbs in the bright field on day 2. B: The forelimbs in the green fluorescent field on day 2. C: The forelimbs in the red fluorescent field on day 2. D: The forelimbs dyed with calcein in the bright field on day 14. E: The forelimbs dyed with calcein in the green fluorescent field on day 14. F: The forelimbs dyed with calcein in the red fluorescent field on day 14.

Fig. 8. The effects of HIF-1 $\alpha$ on BMP2-induced skeletal development as determined by the fetal limb culture assay. A: Histological analysis of the cultured forelimbs. The forelimbs were subjected to H\&E staining. Representative images are shown (100X). B: The average lengths of the hypertrophic zones, prehypertropic zones, and proliferating zones were determined using Image J software. C: The green fluorescence (calcein staining) signal in the ulna of a cultured limb (40X). D: A quantitative analysis of the bone-forming activity (based on calcein incorporation) was conducted using Image J. Hyp = hypertrophic chondrocyte zone, Pre = prehypertropic chondrocyte zones, Pro = proliferating chondrocyte zone . The data us denoted in terms of mean \pm SD. *: $P<0.05$, BMP2 vs. BMP2+HIF$1 \alpha$.

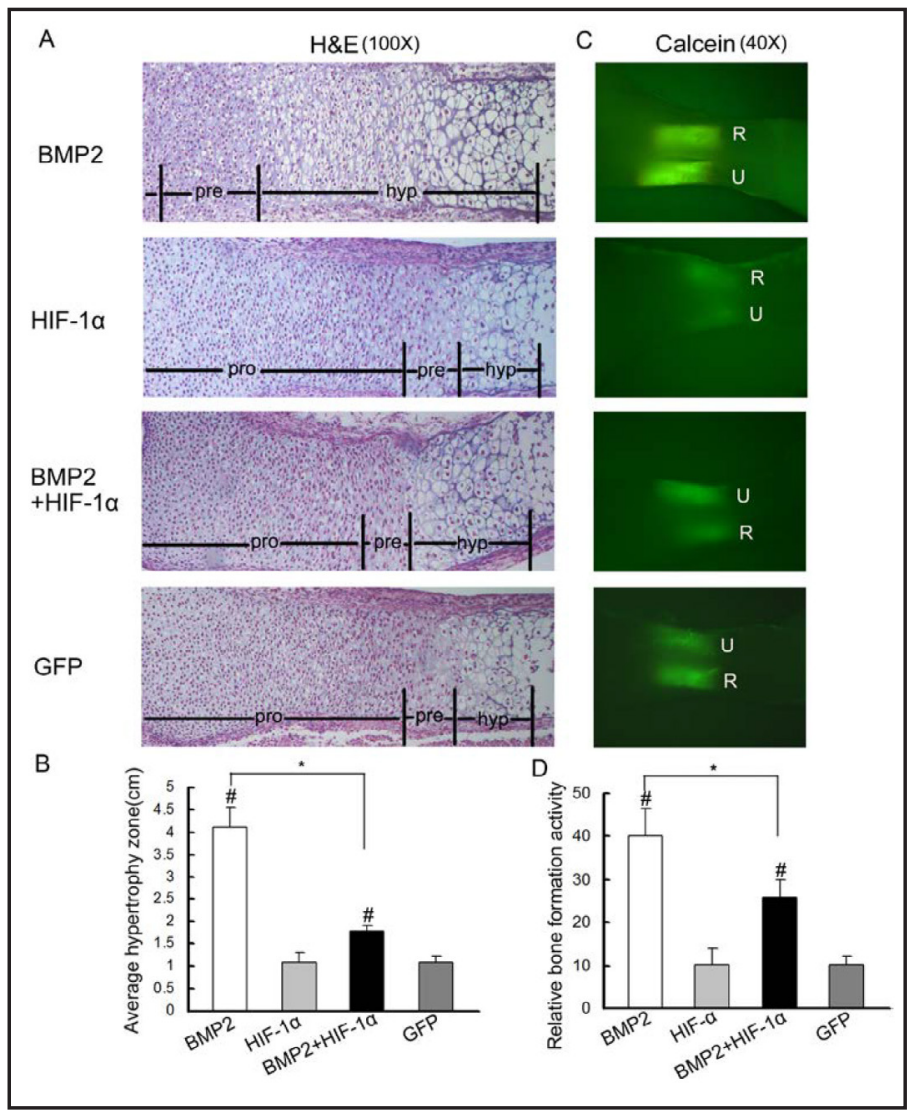

days. The limbs were successfully infected with indicated recombinant adenoviruses on day two (Figs. 7A-C). The ossification of new bone was traced by the fluorescent dye, calcein, on day fourteen (Figs. 7D-F).

Based on the histological examination, BMP2 induced chondrocyte proliferation, hypertrophy, and endochondral ossification. When the limbs were co-infected with AdBMP2 
and AdHIF-1 $\alpha$, the proliferating chondrocyte zones expanded while the hypertrophic chondrocyte zone did not (Fig. 8A). The quantitative analysis of the histologic data also indicated that the hypertrophic chondrocyte zone treated with BMP2 and HIF-1 $\alpha$ was shorter than that treated with BMP2 alone $(P<0.05)$ (Fig. 8B). The limb treated with bothBMP2 and HIF- $1 \alpha$ exhibited less bone formation than that treated with BMP2 alone, as shown by the calcein uptake $(P<0.05)$ (Figs. 8C-D).

These results suggested that HIF- $1 \alpha$ promoted the expansion of the proliferating chondrocyte zone and inhibited BMP2-induced chondrocyte hypertrophy and endochondral ossification in the fetal limb.

\section{Disscussion}

Stem-cell-based, gene-enhanced cartilage tissue engineering could be a feasible alternative to cartilage repair [1,2]. BMP2 has been shown to be capable of inducing chondrogenic differentiation in MSCs [22, 24-26]. However, maintaining the phenotypes of MSCs during cartilage repair is very difficult due to the differentiation that occurs along the endochondral ossification pathway during that process [41]. In this study, HIF$1 \alpha$ was selected as a regulator of BMP2-induced chondrogenic differentiation, osteogenic differentiation, and endochondral bone formation. HIF- $1 \alpha$ was found to potentiate BMP2induced MSCs chondrogenic differentiation and inhibit osteogenic differentiation and endochondral ossification. This regulation could allow for the maintenance of hyaline-like cartilage phenotypes cartilage tissue engineering.

Mesenchymal stem cells differentiate into the chondrocytes that form hyaline cartilaginous matrices, which serve as templates for epiphyseal growth plate formation. Since these events occur during an avascular period in a hypoxic environment, hypoxia seems to be one component of chondrogenesis regulation. Hypoxia has been reported to enhance chondrogenic differentiation in C3H10T1/2 cells by up-regulating collagen II and aggrecan and suppress hypertrophy by down-regulating collagen X via Runx2 inhibition [42]. The expansion of adipose-derived human MSCs under hypoxic conditions has also been proven to suppress hypertrophic phenotypes by downregulating Runx2 and other proteins [43]. HIF- $1 \alpha$, one of the major mediators of hypoxic responses, appears to be essential to chondrogenic differentiation [44] and the maintenance of cartilage phenotypes [40]. In fact, HIF-1a stabilization has become a promising method of cartilage phenotype maintenance in normoxic conditions [33]. Thus, HIF- $1 \alpha$ could be a promising therapeutic tool for future cell-based therapy applications involving cartilage tissue engineering [40].

In this study, BMP2 was found to induce both osteogenic and chondrogenic processes in C3H10T1/2 cells in vitro. When the HIF-1 $\alpha$ expression was upregulated during the BMP2-induced chondrogenic differentiation process in vitro, the HIF-1 $\alpha$ potentiated BMP2induced chondrogenesis. In addition, the Sox9 expression was significantly upregulated by HIF- $1 \alpha$. Sox 9 a transcription factor of the sex-determining region on the Y chromosome (SRY), which regulates sex determination, chondrocyte differentiation, and numerous other developmental events [45]. During cartilage development, Sox9 is expressed in all chondroprogenitor cells; it is essential for the formation of cartilage blastema in limb mesenchyme, proliferation, chondrocyte differentiation in fetal growth plate, and the regulation of cartilage-specific genes, such as Col2A1 and aggrecan [46, 47]. Thus, Col2A1 and aggrecan, the major structural proteins of hyaline cartilage matrices, were significantly upregulated by HIF- $1 \alpha$ as the Sox 9 was upregulated. These results were consistent with our previously published data, revealing that the direct exogenous over expression of Sox 9 could significantly enhance BMP2-induced chondrogenic differentiation [48].

HIF-1 $\alpha$ also inhibited BMP2-induced osteogenesis in vitro. The expression of the Runx2 and downstream markers were significantly downregulated by HIF-1 $\alpha$. Runx 2 is necessary for chondrocyte terminal differentiation [49], osteogenic differentiation, and bone formation during the later stages of embryonic development [28]. Thus, targeting Runx2 expression 


\section{Cellular Physiology Cell Physiol Biochem 2015;36:44-60

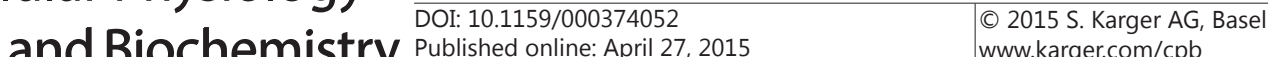 \\ Zhou et al.: HIF-1 $\alpha$ Regulates BMP2-Induced Osteochondrogenic Differentiation}

in hypertrophic chondrocytes impairs endochondral ossification during early skeletal development [28]. Moreover, in our previous study, the over expression of Sox9 resulted in the downregulation of Runx2 expression and the inhibition of BMP-induced osteogenic differentiation and endochondral ossification. Therefore, the downregulation of Runx2 expression could be an efficient method of inhibiting chondrocyte terminal differentiation and osteogenic differentiation. Since Runx2 is essential for early chondrogenesis, which consists of mesenchymal cell condensation, proliferation, and differentiation, during the early stages of embryogenesis [50], suppressing its expression rather than completely removing it could be a more appropriate method during cartilage tissue engineering. Thus, HIF- $1 \alpha$ satisfactorily regulated the inhibition of BMP-induced osteogenic differentiation and could adequately maintain chondrocyte phenotypes in vivo.

In this study, the regulation functions of HIF-1 $\alpha$ during BMP2-induced osteochondrogenic differentiation were investigated via subcutaneous stem cell implantation in nude mice, and the effects of HIF-1 $\alpha$ on the progression of BMP2-induced chondrogenesis and endochondral ossification were observed using a fetal limb culture. Through bone mass histology assay, HIF- $1 \alpha$ was shown to inhibit the BMP2-induced formation of bone matrices, trabeculae, and endochondral ossification, resulting in the maintenance of the cartilage phenotypes in vivo. These results were consistent with the data indicating that HIF- $1 \alpha$ inhibited BMP2induced osteogenic differentiation in vitro. Since chondrocyte hypertrophy is one of the key physiological processes involved in the longitudinal growth of long bones, the use of hypertrophy to prevent endochondrol ossification has become essential to the clinical applications of MSCs in cartilage tissue engineering [33]. In order to precisely observe the effects of HIF- $1 \alpha$ on the BMP2-induced progression of chondrogenesis and endochondral ossification, a fetal limb culture was performed. Fetal limb cultures can mimic the progression of chondrogenesis and endochondral ossification in vitro $[38,51,52]$. The results revealed that HIF- $1 \alpha$ and BMP2 acted synergistically inin expanding the proliferating chondrocyte zone and inhibiting the BMP2-induced chondrocyte hypertrophy and endochondral ossification zone. These results were consistent with published data in that hypoxia suppressed terminal chondrocyte differentiation during endochondral ossification, during which HIF- $1 \alpha$ was the master hypoxia regulator [42]. The results also further indicated that HIF- $1 \alpha$ successfully inhibited BMP2-induced endochondral ossification and maintained the chondrocyte phenotypes.

Several studies have emphasized the importance of extracellular matrices (ECMs) during tissue engineering. Cell-specific ECMs have been reported to be capable of modulating the BMP2-induced osteogenic and chondrogenic differentiation of hMSCs [24]. In this study, only the effects of HIF-1 $\alpha$ on BMP2-induced chondrogenic differentiation, osteogenic differentiation, and endochondral ossification were explored. In future studies, ECMs will be considered in order to further explore the applications of BMP2 to cartilage tissue engineering.

\section{Conclusions}

In this study, HIF- $1 \alpha$ was systematically investigated as a regulator of BMP2-induced chondrogenic differentiation and osteogenic differentiation in vitro and in vivo, and the effects of HIF-1 $\alpha$ on the BMP2-induced progression of chondrogenesis and endochondral ossification was explored using a fetal limb culture assay. Based on the results of these studies, HIF$1 \alpha$ was determined to potentiate BMP2-induced MSC chondrogenic differentiation, inhibit osteogenic differentiation and endochondral ossification, and maintain hyaline cartilage phenotypes. These findings strongly suggested that BMP2 combined with HIF- $1 \alpha$ induced MSC differentiation could become a new method of maintaining cartilage phenotypes during cartilage tissue engineering. 


\section{Cellular Physiology Cell Physiol Biochem 2015;36:44-60

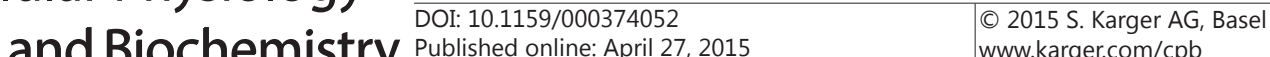

\section{Acknowledgements}

We would like to thank everyone from the Department of Clinical Hematology at Third Military Medical University. We would also like to thank TC He from the Molecular Oncology Laboratory in the Department of Orthopedic Surgery at the University of Chicago for his donation of adenoviruses. This study was supported by research grants from the Natural Sciences Foundation of China (\#31070875 and \#81371972 to Wei Huang).

\section{Disclosure Statement}

The authors declare no conflict of interest.

\section{References}

1 Bhardwaj N, Devi D, Mandal BB: Tissue-Engineered Cartilage: The Crossroads of Biomaterials, Cells and Stimulating Factors. Macromol Biosci DOI:10.1002/mabi.

2 Makris EA, Gomoll AH, Malizos KN, Hu JC, Athanasiou KA: Repair and tissue engineering techniques for articular cartilage. Nat Rev Rheumatol DOI: 10.1038/nrrheum.

-3 Benthien JP, Schwaninger M, Behrens P: We do not have evidence based methods for the treatment of cartilage defects in the knee. Knee Surg Sports Traumatol Arthrosc 2011;19:543-552.

-4 Carlberg AL, Pucci B, Rallapalli R, Tuan RS, Hall DJ: Efficient chondrogenic differentiation of mesenchymal cells in micromass culture by retroviral gene transfer of BMP-2. Differentiation 2001;67:128-138.

-5 Prockop DJ, Sekiya I, Colter DC: Isolation and characterization of rapidly self-renewing stem cells from cultures of human marrow stromal cells. Cytotherapy 2001;3:393-396.

6 Nöth U, Osyczka AM, Tuli R, Hickok NJ, Danielson KG, Tuan RS: Multilineage mesenchymal differentiation potential of human trabecular bone-derived cells. J Orthop Res 2002;20:1060-1069.

-7 Zuk PA, Zhu M, Mizuno H, Huang J, Futrell JW, Katz AJ, Benhaim P, Lorenz HP, Hedrick MH: Multilineage cells from human adipose tissue: implications for cell-based therapies. Tissue Eng 2001;7:211-228.

8 Ferretti C, Mattioli-Belmonte M: Periosteum derived stem cells for regenerative medicine proposals: Boosting current knowledge. World J Stem Cells 2014;6:266-277.

-9 Kobayashi S, Takebe T, Zheng YW, Mizuno M, Yabuki Y, Maegawa J, Taniguchi H: Presence of cartilage stem/ progenitor cells in adult mice auricular perichondrium. PLoS One 2011;6:e26393.

10 Sanchez-Adams J, Athanasiou KA: Dermis isolated adult stem cells for cartilage tissue engineering. Biomaterials 2012;33:109-119.

11 Li D, Zhu H, Liang C, Li W, Xing G, Ma L, Ding L, Zhang Y, He F, Zhang L: CKIP-1 suppresses the adipogenesis of mesenchymal stem cells by enhancing HDAC1-associated repression of C/EBP $\alpha$. J Mol Cell Biol 2014;6:368-379.

12 Longo UG, Petrillo S, Franceschetti E, Berton A, Maffulli N, Denaro V: Stem cells and gene therapy for cartilage repair. Stem Cells Int 2012;2012:168385.

13 Deng ZL, Sharff KA, Tang N, Song WX, Luo J, Luo X, Chen J, Bennett E, Reid R, Manning D, Xue A, Montag AG, Luu HH, Haydon RC, He TC: Regulation of osteogenic differentiation during skeletal development. Front Biosci 2008;1:2001-2021.

-14 Pelttari K, Steck E, Richter W: The use of mesenchymal stem cells for chondrogenesis. Injury 2008;39 Suppl 1:S58-65.

15 Caplan AI, Elyaderani M, Mochizuki Y, Wakitani S, Goldberg VM: Principles of cartilage repair and regeneration. Clin Orthop Relat Res 1997;342:254-269.

16 Dahlin RL, Ni M, Meretoja VV, Kasper FK, Mikos AG: TGF- $\beta 3$-induced chondrogenesis in co-cultures of chondrocytes and mesenchymal stem cells on biodegradable scaffolds. Biomaterials 2014;35:123-132.

17 Li J, Wang J, Zou Y, Zhang Y, Long D, Lei L, Tan L, Ye R, Wang X, Zhao Z: The influence of delayed compressive stress on TGF- $\beta 1$-induced chondrogenic differentiation of rat BMSCs through Smad-dependent and Smadindependent pathways. Biomaterials 2012;33:8395-8405. 


\section{Cellular Physiology Cell Physiol Biochem 2015;36:44-60

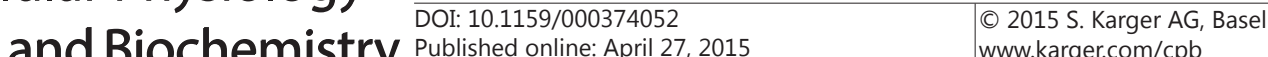 \\ Zhou et al.: HIF-1 $1 \alpha$ Regulates BMP2-Induced Osteochondrogenic Differentiation}

18 Kakoi H, Maeda S, Shinohara N, Matsuyama K, Imamura K, Kawamura I, Nagano S, Setoguchi T, Yokouchi M, Ishidou Y, Komiya S: Bone morphogenic protein (BMP) signaling up-regulates neutral sphingomyelinase 2 to suppress chondrocyte maturation via the Akt protein signaling pathway as a negative feedback mechanism. J Biol Chem 2014;289:8135-8150.

19 Yoon BS, Lyons KM: Multiple functions of BMPs in chondrogenesis. J Cell Biochem 2004;93:93-103.

20 Handorf AM, Li WJ: Fibroblast growth factor-2 primes human mesenchymal stem cells for enhanced chondrogenesis. PloS one 2011;6:e22887.

21 Patil AS, Sable RB, Kothari RM: Role of insulin-like growth factors (IGFs), their receptors and genetic regulation in the chondrogenesis and growth of the mandibular condylar cartilage. J Cell Physiol 2012;227:1796-1804.

22 An C, Cheng Y, Yuan Q Li J: IGF-1 and BMP-2 induces differentiation of adipose-derived mesenchymal stem cells into chondrocytes-like cells. Ann Biomed Eng 2010;38:1647-1654.

23 Shu B, Zhang M, Xie R, Wang M, Jin H, Hou W, Tang D, Harris SE, Mishina Y, O'Keefe RJ, Hilton MJ, Wang Y, Chen D: BMP2, but not BMP4, is crucial for chondrocyte proliferation and maturation during endochondral bone development. J Cell Sci 2011;124:3428-3440.

24 Kwon SH, Lee TJ, Park J, Hwang JE, Jin M, Jang HK, Hwang NS, Kim BS: Modulation of BMP-2-induced chondrogenic versus osteogenic differentiation of human mesenchymal stem cells by cell-specific extracellular matrices. Tissue Eng Part A 2013;19:49-58.

25 Pan Q Yu Y, Chen Q, Li C, Wu H, Wan Y, Ma J, Sun F: Sox9, a key transcription factor of bone morphogenetic protein-2-induced chondrogenesis, is activated through BMP pathway and a CCAAT box in the proximal promoter. J Cell Physiol 2008;217:228-241.

-26 Kurth T, Hedbom E, Shintani N, Sugimoto M, Chen FH, Haspl M, Martinovic S, Hunziker EB: Chondrogenic potential of human synovial mesenchymal stem cells in alginate. Osteoarthritis Cartilage 2007;15:11781189.

-27 Bae JS, Gutierrez S, Narla R, Pratap J, Devados R, van Wijnen AJ, Stein JL, Stein GS, Lian JB, Javed A: Reconstitution of Runx2/Cbfa1-null cells identifies a requirement for BMP2 signaling through a Runx2 functional domain during osteoblast differentiation. J Cell Biochem 2007;100:434-449.

28 Ding M, Lu Y, Abbassi S, Li F, Li X, Song Y, Geoffroy V, Im HJ, Zheng Q: Targeting Runx2 expression in hypertrophic chondrocytes impairs endochondral ossification during early skeletal development. J Cell Physiol 2012;227:3446-3456.

29 Keith B, Simon MC: Hypoxia-inducible factors, stem cells, and cancer. Cell 2007;129:465-472.

- 30 Duval E, Baugé C, Andriamanalijaona R, Bénateau H, Leclercq S, Dutoit S, Poulain L, Galéra P, Boumédiene K: Molecular mechanism of hypoxia-induced chondrogenesis and its application in in vivo cartilage tissue engineering. Biomaterials 2012;33:6042-6051.

-31 Zhang C, Yang F, Cornelia R, Tang W, Swisher S, Kim H: Hypoxia-inducible factor-1 is a positive regulator of Sox9 activity in femoral head osteonecrosis. Bone 2011;48:507-513.

- 32 Robins JC, Akeno N, Mukherjee A, Dalal RR, Aronow BJ, Koopman P, Clemens TL: Hypoxia induces chondrocyte-specific gene expression in mesenchymal cells in association with transcription activiation of Sox9. Bone 2005;37:313-322.

33 Yang DC, Yang MH, Tsai CC, Huang TF, Chen YH, Hung SC: Hypoxia inhibits osteogenesis in human mesenchymal stem cells through direct regulation of RUNX2 by TWIST. PLoS One 2011;6:e23965.

-34 Studer D, Millan C, Öztürk E, Maniura-Weber K, Zenobi-Wong M: Molecular and biophysical mechanisms regulating hypertrophic differentiation in chondrocytes and mesenchymal stem cells. Eur Cell Mater 2012;24:118-135.

- 35 Luo J, Deng ZL, Luo X, Tang N, Song WX, Chen J, Sharff KA, Luu HH, Haydon RC, Kinzler KW, Vogelstein B, He TC: A protocol for rapid generation of recombinant adenoviruses using the AdEasy system. Nat Protoc 2007;2:1236-1247.

-36 Takács R, Matta C, Somogyi C, Juhász T, Zákány R: Comparative analysis of osteogenic/chondrogenic differentiation potential in primary limb bud-derived and C3H10T1/2 cell line-based mouse micromass cultures. Int J Mol Sci 2013;14:16141-16167.

-37 Denker AE, Haas AR, Nicoll SB, Tuan RS: Chondrogenic differentiation of murine C3H10T1/2 multipotential mesenchymal cells: I. Stimulation by bone morphogenetic protein-2 in high-density micromass cultures. Differentiation 1999;64:67-76. 


\section{Cellular Physiology Cell Physiol Biochem 2015;36:44-60

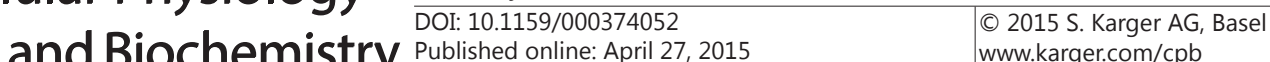 \\ Zhou et al.: HIF-1 $\alpha$ Regulates BMP2-Induced Osteochondrogenic Differentiation}

38 Chen L, Jiang W, Huang J, He BC, Zuo GW, Zhang W, Luo Q, Shi Q, Zhang BQ, Wagner ER, Luo J, Tang M, Wietholt C, Luo X, Bi Y, Su Y, Liu B, Kim SH, He CJ, Hu Y, Shen J, Rastegar F, Huang E, Gao Y, Gao JL, Zhou JZ, Reid RR, Luu HH, Haydon RC, He TC, Deng ZL: Insulin-like growth factor 2 (IGF-2) potentiates BMP-9induced osteogenic differentiation and bone formation. J Bone Miner Res 2010;25:2447-2459.

-39 Hu N, Jiang D, Huang E, Liu X, Li R, Liang X, Kim SH, Chen X, Gao JL, Zhang H, Zhang W, Kong YH, Zhang J, Wang J, Shui W, Luo X, Liu B, Cui J, Rogers MR, Shen J, Zhao C, Wang N, Wu N, Luu HH, Haydon RC, He TC, Huang W: BMP9-regulated angiogenic signaling plays an important role in the osteogenic differentiation of mesenchymal progenitor cells. J Cell Sci 2013;126:532-541.

-40 Duval E, Leclercq S, Elissalde JM, Demoor M, Galéra P, Boumédiene K: Hypoxia-inducible factor 1 inhibits the fibroblast-like markers type I and type III collagen during hypoxia-induced chondrocyte redifferentiation. Arthritis Rheum 2009;60:3038-3048.

41 Pelttari K, Winter A, Steck E, Goetzke K, Hennig T, Ochs BG, Aigner T, Richter W: Premature induction of hypertrophy during in vitro chondrogenesis of human mesenchymal stem cells correlates with calcification and vascular invasion after ectopic transplantation in SCID mice. Arthritis Rheum 2006;54:3254-3266.

-42 Hirao M, Tamai N, Tsumaki N, Yoshikawa H, Myoui A: Oxygen tension regulates chondrocyte differentiation and function during endochondral ossification. J Biol Chem 2006;281:31079-31092.

43 Xu Y, Malladi P, Chiou M, Bekerman E, Giaccia AJ, Longaker MT: In vitro expansion of adipose-derived adult stromal cells in hypoxia enhances early chondrogenesis. Tissue Eng 2007;13:2981-2993.

44 Kanichai M, Ferguson D, Prendergast PJ, Campbell VA: Hypoxia promotes chondrogenesis in rat mesenchymal stem cells: a role for AKT and hypoxia-inducible factor (HIF)-1alpha. J Cell Physiol 2008;216:708-715.

45 Lefebvre V, Dumitriu B, Penzo-Mendez A, Han Y, Pallavi B: Control of cell fate and differentiation by Sryrelated high-mobility-group box (Sox) transcription factors. Int J Biochem Cell Biol 2007;39:2195-2214.

-46 de Crombrugghe B, Lefebvre V. Nakashima K: Regulatory mechanisms in the pathways of cartilage and bone formation. Curr Opin Cell Biol 2001;13:721-27.

-47 Lefebvre V, Smits P: Transcriptional control of chondrocyte fate and differentiation. Birth Defects Res C Embryo Today 2005;75:200-212.

48 Liao J, Hu N, Zhou N, Lin L, Zhao C, Yi S, Yi S, Fan T, Bao W, Liang X, Chen H, Xu W, Chen C, Cheng Q, Zeng Y, Si W, Yang Z, Huang W: Sox9 potentiates BMP2-induced chondrogenic differentiation and inhibits BMP2induced osteogenic differentiation. PLoS One 2014;9:e89025.

49 Ding M, Lu Y, Abbassi S, Li F, Li X, Song Y, Geoffroy V, Im HJ, Zheng Q: Targeting Runx2 expression in hypertrophic chondrocytes impairs endochondral ossification during early skeletal development. J Cell Physiol 2012;227:3446-3456.

50 Kim EJ, Cho SW, Shin JO, Lee MJ, Kim KS, Jung HS: Ihh and Runx2/Runx3 signaling interact to coordinate early chondrogenesis: a mouse model. PLoS One 2013;8:e55296.

-51 Hu N, Wang C, Liang X, Yin L, Luo X, Liu B, Zhang H, Shui W, Nan G, Wang N, Wu N, Chen X, He Y, Wen S, Deng F, Zhang H, Liao Z, Luu HH, Haydon RC, He TC, Huang W: Inhibition of histone deacetylases potentiates BMP9-induced osteogenic signaling in mouse mesenchymal stem cells. Cell Physiol Biochem 2013;32:486498.

-52 Wang JH, Liu YZ, Yin LJ, Chen L, Huang J, Liu Y, Zhang RX, Zhou LY, Yang QJ, Luo JY, Zuo GW, Deng ZL, He BC: BMP9 and COX-2 form an important regulatory loop in BMP9-induced osteogenic differentiation of mesenchymal stem cells. Bone 2013;57:311-321. 